Publicado en 2011; Journal of Hydrology 405(3-4): 427-438.

\title{
Electromagnetic induction as a basis for soil salinity monitoring within a
}

\section{Mediterranean irrigation district}

\author{
J. Herrero ${ }^{a,},{ }^{*}$ A. Netthisinghe ${ }^{\mathrm{b}}$, W.H. Hudnall ${ }^{\mathrm{b}}$, O. Pérez-Coveta ${ }^{\mathrm{a}}$ \\ ${ }^{a}$ Estación Experimental de Aula Dei, CSIC, PO Box 13034, 50080 Zaragoza, Spain \\ ${ }^{b}$ Dep. of Plant and Soil Science, Texas Tech University, Lubbock, TX 79409, USA
}

\begin{abstract}
Soil salinity encroachment is an increasing concern in many irrigated lands, because of the 10 undesirable effects of soluble salts on agricultural production and on water quality. From this point of view, the design and management of irrigation districts can be evaluated by monitoring the soil salinity. There are few cases in the world where comparisons can be undertaken from 'historic' data sets for extents other than individual plots. We demonstrate a monitoring procedure using electromagnetic induction (EMI) survey in an irrigated district in Spain. This district is the only one having an established soil salinity baseline. The EMI data acquired at the same plots were converted to soil electrical conductivity by calibrating with augered soil samples. The presented calibrations improve the baseline for future comparisons and for the treatment and understanding of new acquisitions of field data in next surveys. A shortcoming inherent to destructive soil sampling is its potential for biasing effects on long-term monitoring of soil salinity by means of GPS or other means of accurate localization and relocalization of soil sampling, the herein called "localization paradox", rarely treated in scientific papers. The localization paradox is relevant for any variable soil property requiring repeated sampling. This issue is discussed, and a way for its overcoming by using EMI readings displaced from the augering is presented. EMI needs calibration with a reduced number of soil samples analyzed in the lab. The adoption of our data treatment procedures will facilitate soil salinity monitoring.
\end{abstract}

Keywords: Irrigation; Flumen district; Spain

Abbreviations: ECe: Electrical conductivity of the extract of saturated paste; ECe100: ECe of the upper $100 \mathrm{~cm}$ of the soil; ECemaxd: ECe up to the maximum depth reached in augerings shallower than $1 \mathrm{~m}$; EDA: exploratory data analysis; EM38: a model of electromagnetic sensor; EMH and EMV: uncorrected reading in EM38 at the horizontal and vertical orientation of the coils; EMh and EMv: reading in EM38 corrected by soil temperature and divided by 100, at the horizontal and vertical positions of the coils; EMI: electromagnetic induction; GPS: global positioning system; IRYDA: acronym of the late Institute in charge of irrigation projects in Spain; Wa: actual gravimetric water content percent of the soil; Wa100: Wa of the upper $100 \mathrm{~cm}$ of the soil; Wadrill: Wa up to the drilling depth.

* Corresponding author. Fax: +34 976716 145; E-mail: jhi@eead.csic.es 


\section{Introduction}

Soil salinity in arid countries often results from the salt concentrating at the surface by evapotranspiration. Soil salinity differences can occur within small horizontal or vertical distances and also with time, both seasonally and within a span of several years. Agricultural production of countries that have arid climatic conditions relies on irrigation, but soil salinity can curtail crop profitability. Moreover, movement of salts with water increases the spatial and temporal variability of salt content in the soil, and allows exportation of salts from the irrigation district. Thus, soil salinity of irrigated lands is undesirable from the production and environmental points of view.

Inadequate irrigation scheme design, or mismanagement of the irrigation water, can lead to a decrease in production (Ghassemi et al., 1995; Young, 1998; Derici, 2002) and soil degradation, which can be technically irreversible if soil sodicity occurs (Sumner and Naidu, 1998). The irrigated district of Flumen, located in the Ebro river basin, NE Spain, is a good example of the agricultural and environmental effects of soil salinity.

The requirements of assessing the evolution of salinity of irrigated districts will increase as land and water become a more and more disputed resources. For this assessment, the soil salt content and its evolution over time must be investigated, either by direct soil sampling or by other measuring techniques. The most feasible, for most situations, is to survey by electromagnetic induction (EMI) measurements.

The EM38 (Geonics Ltd., Ontario, Canada), is a hand-held sensor that has two parallel coils, which reads the electromagnetic response of its surrounding space. For a given soil, this response varies with moisture, salt content, and temperature. Obtaining EM38 values are easy because the instrument does not need to be in contact with the soil. If the EM38 is oriented in the horizontal position, the reading mainly accounts for the conductivity of the first meter of the soil. When the coils are in the vertical orientation, the electrical conductance of the soil layers to a $2 \mathrm{~m}$ depth is recorded. The EM38 must be calibrated by determining soil salinity from soil samples taken immediately after the EMI reading at some of the surveyed sites in order to obtain a valid soil salinity survey. The EMI readings must be conducted at adequate soil moisture content to maximize the harmonic structure of the emitted electromagnetic wave at each wave emission location.

Soil salinity can vary within a few meters in the area of interest, which compromises the validity of representative auger samples. EMI readings can reduce this problem, because of the larger soil volume explored. 
EMI has been applied for different regions of the world to map the soil salinity of individual plots (Corwin and Plant, 2005). This was the case for the Ebro valley (Amezketa, 2006) and specifically for the Flumen irrigation district (López-Bruna and Herrero, 1996; Lesch et al., 1998; Herrero et al., 2003). The EM38 successfully mapped soil salinity of small plots $(<1 \mathrm{ha})$. However, an approach that focused upon soil salinity contour lines would not make sense for broad areas of this district, which encompasses contrasting soils and thousands of irrigated plots with different soils, crops, management, and irrigation timing. For these conditions, we mapped soil salinity phases using EMI (Nogués et al., 2006) which produced a map useful for upgrading the irrigation system (Herrero et al., 2007). All these work regress the soil electrical conductivity determined from saturation paste extracts (ECe) on the EM38 readings to convert the EMI data into soil salinity. This calibration procedure is easy and its efficacy is the standard as evidenced by the many references and the review of Rhoades et al. (1999). There are very few cases in the world where entirely valid comparisons of soil salinity are possible from 'historic' data sets. Some cases were reviewed by Herrero and Pérez-Coveta (2005). The article also raises a matter of interest for all surveys using EM38 or similar EMI devices on areas with broad range of EMI readings: how the use of one or other calibration dial influences the range of readings at a given site.

The assessment of soil salinization or desalinization has been undertaken at different scales by several authors, as reviewed by Herrero and Pérez-Coveta (2005). These studies involved different intensities of destructive soil samplings by auger or other procedures. Studies like those of De Clerck et al. (2003) or Herrero and Pérez-Coveta (2005) are based upon plot locations sampled decades earlier, and resampled for comparison. The paired sampling approach aim is not to depict the spatial variability of the soils, nor to allow modelbased sampling strategies (Lesch, 2005) or classical geostatistical procedures. However; it is easy and feasible where previous soils data are scarce, a frequent circumstance.

The correct site location for resampling is critical, but difficult because many previous sample locations were completed without maps at adequate scale and were not georeferenced. Today, the location of new sample sites is simple with global positioning systems (GPS) or other topographic instruments with centimetric accuracy locations, if desired. Otherwise, soil destructive sampling plus accurate location can lead to a "localization paradox" in soil salinity or other monitoring operations that involve destructive sampling. Field observations (Herrero, 2008) have shown for years the durability of auger holes or other remaining soil discontinuities produced by soil sampling. One can suppose that these discontinuities or their remnants remain 
as preferential water paths for many years, leading to a local artifactal concentration or dilution of salts. This can occur, even in cultivated fields, at depths below routine plowing. With the precision available by current GPS or other technologies, if the discontinuity is not recognized during future samplings at the previous locations, biased data would be obtained. We used several EM38 readings around each auger hole to examine the reliability of EMI readings.

110 They were intentionally not exactly located on the augering point as a way to overcome the "localization paradox". This drawback has not been previously treated, to our knowledge, in the literature.

The objectives of this study were to (i) show the suitability of EMI techniques for the diagnosis of soil salinity within an irrigation district for monitoring purposes, (ii) generate soil salinity data as a baseline for comparison with future or precedent surveys, and (iii) demonstrate a sampling methodology that avoids field artifacts inherited from previous soil surveys.

\section{Location and description of the studied area}

Flumen irrigation district is located in the Ebro valley, Northeastern Spain (Figure 1). The study area (27500 ha), is enclosed by the Flumen Canal and the Alcanadre and Flumen Rivers. Most of the land has been irrigated for more than 50 years with water from the Pyrenees delivered by the Flumen Canal, a derivation of the Monegros Canal. The electrical conductivity of the water from the Flumen Canal is $<0.4 \mathrm{dS} \mathrm{m}^{-1}$, and the sodium adsorption ratio $(\mathrm{SAR})<1$.

Martínez-Cob et al. (1998) used data from the the Grañén-Sodeto weather station and calculated the annual averages of temperature, precipitation, and evapotranspiration (Blaney Criddle FAO), as $14.4{ }^{\circ} \mathrm{C}, 525 \mathrm{~mm}$, and $1253 \mathrm{~mm}$, respectively. The soil moisture regime is xeric or aridic, depending on the water holding capacity of the profile.

Rocks are of Miocene age, mainly alternating sandstone and lutite, which are often saliferous. These materials and their hydraulic characteristics favor lateral water fluxes and salt accumulation in depressed areas, which are filled with Holocene microlaminated sediments. Quaternary-aged gravels were deposited on Miocenic materials. Slopes are heterogeneous, with both Miocenic-aged materials and colluvium derived from the Quaternary-aged materials capping most mesas.

The soil map at scale 1:100000 (Nogués, 1994) and a quantitative soil salt-affected appraisal (Table 1) record several geomorphic units of the irrigated area (Figure 2). The mesas 
soils are salt-free, stony and well drained. There are patches that are so stony and/or have a shallow petrocalcic horizon that cultivation is hindered. Soils on the slopes are heterogeneous because soils were moved in order to construct and level plots for basin and border irrigation and resultant fields are often moderately saline or saline-sodic. Most river terraces have coarse detritic materials, and the soils are non-saline and well drained, excepted for some patches with medium-textured materials that have saline-sodic soils with imperfect drainage. Soils of the bottoms are moderately deep, strongly saline and sodic, fine- and medium-textured, and imperfectly drained. They are extensively used for rice production.

Natural vegetation only appears as small spots on marginal lands. Halophytes occur in depressions, and are good salt indicators; the most common are: Atriplex halimus L., Plantago coronopus L. Puccinellia sp., Salicornia ramosissima J. Woods, Spergularia media (L.) K. Presl, and Suaeda vera Forsskål ex J.F. Gmelin.

150 The typical size of the flood-irrigated plots is $<1$ ha, but recently some plots have been combined to attain an adequate size for upgrading to sprinkler irrigation. Soil salinity, annual availability of water, and subsidies are the main factors that determine the sowing decision by farmers. Alfalfa, barley, corn, forage, rice, sunflower, and wheat are the most common crops. Rice paddies are generally confined to saline-sodic soils, whose low permeability makes feasible the flooding with running water during the crop cycle.

\section{Materials and methods}

\subsection{Field and lab operations}

Soils of the study area were surveyed during 1975 for irrigation suitability (IRYDA, 1975) by mean of pits and other observations, with special attention to salinity. The same plots were resampled in 1985 by Herrero (1987), and again in 1999 by Herrero and Pérez-Coveta (2005). Nogués (1994) gathered the available information about soils for land evaluation of the irrigated district, which resulted in a soil map.

The field study of 1999 included EMI measurements. These EMI techniques were not presented by Herrero and Pérez-Coveta (2005). The purpose of their study was to allow for more intensive surveys based on EMI in the future. Their purpose was not to establish a more detailed grid, but to check if during future years, EMI could enlarge the number of sites available for comparisons, without increasing the number of augerings.

The studies of 1985 and 1999 purpose were to sample at the same locations as 1975 . To locate the plots, we had the original set of aerial photograph contact prints at 1:12000 scale 
used by the surveyors of 1975, and the location of sampling sites marked by them. In June 1975, the area was flown with 18 tracks of uneven length by Aeropost Co. contracted by IRYDA, and the negatives filed by Aeropost as "FLUMEN (HUESCA) file no. 26/75".

These prints allowed us to locate most of the plots sampled during 1975. The plots with doubtful identification and those with evidence of strong earth movements, or non-irrigated were not resampled. EMI readings were made immediately before augering at the 40 sites having adequate moisture conditions. Figure 1 shows the location of these sites, with two of them superposed at this scale. The coordinates of all sampling sites for 1999 were recorded in the field with a GPS, and pictures taken to register the surface appearance in order to make locating the sample locations in the future easier. The species of the crop and salinity-indicator volunteer plants, the evidences of changes in the irrigation or drainage systems, and other features possible indicators of soil salinity changes in the plot, were recorded.

Survey and field operations were from 19/04/99 to 15/05/99. Soil temperature was measured at $20 \mathrm{~cm}$ and $40 \mathrm{~cm}$ depth for the plots at the time EMI readings were obtained. EM38 readings were taken at the horizontal and vertical coil orientations. A correction factor was applied to the readings according to the measured soil temperature, so as to reference them to $25^{\circ} \mathrm{C}$ (United States Salinity Laboratory Staff, 1954). After dividing them by 100 to simplify the calibration equations, the two corrected readings were named EMh and EMv, respectively. The EMI readings were made at five points for each auger sampling site: the point where the augering was to be made and labelled as central $(C)$, and four more points: north $(N)$, east $(E)$, south (S), and west (W) located $2 \mathrm{~m}$ from $\mathrm{C}$, in the four cardinal directions (Figure 3). An exception was site 62 , where readings from the $\mathrm{W}$ location were not obtained. The uncorrected EMI readings, EMH and EMV, are used to discuss possible distortions of the EMI variability, related to the change of measurement scale for the EM38 dial.

A total of 240 soil samples were taken by an Edelman hand auger. The samples were air-dried and ground using a sieving mill with 2-mm $\varnothing$ holes. Salinity was characterized following United States Salinity Laboratory Staff (1954). The electrical conductivity of the extract of saturated paste (ECe) and of the 1:5 extract (EC1:5) were measured with a Radiometer CDM-83, and expressed as $\mathrm{dS} \mathrm{m}^{-1}$ at $25{ }^{\circ} \mathrm{C}$. These data as well as the percent of saturation, the ionic contents, and $\mathrm{pH}$ of several extracts, were presented and discussed by Herrero and Pérez-Coveta (2005). The same work explains how an ECe was attributed to the different soil depths, by weighting the ECe of the samples according to the depth interval of each sample appropriate to the desired total depth. 
The percentage of gravimetric soil water content (Wa) of the soils samples obtained at the time as the EM38 readings, was determined in the lab on 112 subsamples taken using tared hermetic cans, corresponding to 31 complete augerings. The gravimetric water content at -33 $\mathrm{kPa}$ and at $-1500 \mathrm{kPa}$ was also determined for these 112 samples using ceramic plates pressure equipment, to check if Wa was within this range. The calculation of gravimetric water content for the desired depths was made by the same procedure as that used for ECe. Wa up to the maximum reached depth (Wadrill) was used as a surrogate of Wa100 for some drillings that were shallower than $100 \mathrm{~cm}$. Gravimetric water content determinations are expressed as $\% \mathrm{w} / \mathrm{s}$, i.e., mass of water per hundred units mass of dry soil.

\subsection{Different approaches for EM38 calibration}

Several issues were taken into account for the assayed calibrations: (i) soil moisture 215 content at the time of EMI survey, (ii) effect of the soil lateral variability within $2 \mathrm{~m}$ radius of the sampling points, (iii) different soil depth, (iv) historical soil salinity status of the sites, and (v) the grouping of sites according to the soil map units of Nogués (1994).

\subsection{Data analysis}

Exploratory data analyses (EDA) (Tukey, 1977) was performed to characterize the univariate data; to examine the linear model fit for bivariate data; and to detect leverage and outlier data points. EDA graphical analysis included histograms, scatter diagrams, and boxplots (Chambers et al., 1983; Hettmansperger and Sheather, 1986) drawn according to the conventions of Figure 4. In addition, we examined the measures of central tendency for univariate data. Adequate fulfilment of fundamental regression assumptions; independence of observations, linear functional form, presence of influential outliers, non correlated variables, normal and homogeneous regression residuals were checked with graphs and relevant tests. We used the Durbin-Watson test and examined the standardized residual plots to check the independence of observations and regression residuals. Linear ECe/EMI model fit was studied through scatter diagrams. We extracted the standardized residuals and examined them with histograms, quantile-quantile plots and applied the Shapiro-Wilk test to check the normality. Homoscedasticity of regression residuals was investigated by studying the data distribution of the standardized residual plots. Residual plots along with Cook's d and Dfbetas statistics was used to obtain information about leverage of observations residuals, and to assess their influence on model parameters.

Parametric simple linear regression was applied as the first step for the calibrations between ECe and EMI readings (EMh and EMv) and then diagnostic procedures were 
performed. We attempted to correct the violation of normal distribution of the observations and regression residuals using either Log or Box-Cox (Box and Cox, 1964) transformation of ECe. The presence of influential outliers and non-constant residual variance made both the parametric regression analysis, the weighted least square regression method, and the nonparametric regression statistically inappropriate. Hence, we applied robust regression, Least Trimmed Squares (LTS) method (Rousseew and Leroy, 1987). Robust regression analysis generates resistant results for ECe/EMI calibrations with the presence of outliers and regression assumption violations. LTS regression is based upon the subset of $h$ cases (out of $n$ ) whose least squares fit possesses the smallest sum of squared residuals. LTS is a highly robust regression estimator, with a breakdown value $(n-h) / n$.

The ECe weighted 20, 40, 60, 80, and $100 \mathrm{~cm}$ and $150 \mathrm{~cm}$ depths were regressed on $\mathrm{EMh}$ and EMv with the robust LTS regression method and with the ordinary least squares (OLS) regression. We assigned most of our EMI calibrations to the weighted ECe $100 \mathrm{~cm}$ depth (ECe100), which considers the upper meter of the soil as a proper depth for agronomical purposes. Establishing salinity contents for this depth is appropriate because it is the depth of maximum absorption by the roots of most irrigated crops, and is a depth easily reached by hand-augering for most soils of the irrigated district studied. Selection of EMh and EMv as regressors for calibrations of ECe100 and ECe150 was appropriate since the EMI signals at these depths are attributed primarily to the horizontal and vertical orientation readings of the EM38. For the 13 augerings shallower than $1 \mathrm{~m}$, we used ECe weighted to their maximum depth (ECemaxd) for some regressions.

We compared the means of log transformed EMh readings of the five nested points $\mathrm{C}$, $\mathrm{N}, \mathrm{E}, \mathrm{S}$, and $\mathrm{W}$ with one way ANOVA to evaluate the effect of local soil lateral variability around the sampling points. The ECe100 was calibrated with the EMh readings of five locations with OLS method and with the LTS robust regression method. Accordingly, we developed ten regression equations to explain the relationships between ECe100 and EMh at the reading points $\mathrm{C}, \mathrm{N}, \mathrm{S}, \mathrm{E}$, and $\mathrm{W}$. Chow test (Chow, 1960) was used to evaluate the equality between sets of coefficients from two linear regressions.

For a 1-m depth, separate calibrations were established for the sites considered: (i) nonsaline (ECe $<2 \mathrm{dS} \mathrm{m}^{-1}$ ), or (ii) salinity-prone because they had an ECe $\geq 2 \mathrm{dS} \mathrm{m}^{-1}$ from any of the past three soil surveys $(1975,1985$, and 1999) after the data of Herrero and Pérez-Coveta (2005). 
We conducted other separated calibrations for the same depths by grouping the sites according to the soil map units of Nogués (1994) by matching the coordinates of the site to the delineation of the unit. Analysis of covariance using the regression model was used to test the influence of salinity status and soil map unit type on ECe100/EMh regression.

\section{Results and discussion}

\subsection{Distributions of EMI readings and ECe determinations}

Only 31 of the sites augered in 1999 had soil moisture adequate for the EMI reading during the first visit. After repeated field visits, adequate moisture content was found for only 9 additional plots, in spite of the occurrence of a heavy rain. One way to have adequate moisture is to wait a couple of days after irrigation, but in practice it was infeasible to know the irrigation date for each plot. The elapsed time between augering and EMI readings for these nine sites was less than 30 days. We assumed that the variation in soil salinity to $1 \mathrm{~m}$ was inconsequential. This was confirmed by the negligible differences between calibrations for all sampling sites. Table 2 displays the 40 sites used for the calibration.

EMh values ranged from 0.11 to 2.68, and EMv from 0.07 to 2.48 (Table 2). High

colinearity occurs between EMh and EMv, with a correlation coefficient of 98.1 ( $p<0.00)$. ECe100 and shallower depths than $100 \mathrm{~cm}$ (ECe maxd), ranged between 0.53 to $20.34 \mathrm{dS} \mathrm{m}^{-1}$. ECe and EMI readings were much higher at sampling site 15 than for any other sites (Table 2). Moreover, the ECe exceeds $10 \mathrm{dS} \mathrm{m}^{-1}$, which is the upper limit of the EM38 (McNeill, 1980). Both ECe up to the different depths computed and the distribution of EMI readings were found non gaussian (Figures 5 and 6; Shapiro-Wilk test: $\mathrm{p}<0.00$ ). Log transformed EMh readings were normally distributed. However, both Log and Box-Cox transformations failed to correct the skewed ECe distribution data and the transformations did not eliminate the outliers.

\subsection{Soil moisture content of the EMI survey}

Actual gravimetric water content (Wa) ranged from $6 \%$ to $\mathrm{w} / \mathrm{s} 34 \% \mathrm{w} / \mathrm{s}$ for the 112 soil samples taken from the 31 profiles having this measurement (data not presented). Wa ranged between the water retention at $-33 \mathrm{kPa}$ and $-1500 \mathrm{kPa}$ for 82 samples. Twenty eight samples had differences $\leq 5 \% \mathrm{w} / \mathrm{s}$ water content at $-33 \mathrm{kPa}$ and $-1500 \mathrm{kPa}$, and two samples from two different profiles, Wa was $8 \% \mathrm{w} / \mathrm{s}$ and $16 \% \mathrm{w} / \mathrm{s}$ greater than the water retention at $-33 \mathrm{kPa}$, 
and at $-1500 \mathrm{kPa}$ were from the same profile. These allowable differences of individual samples are negligible for soil profiles.

The soil moisture weighted to the 1-m depth (Wa100) ranged from $12.8 \% \mathrm{w} / \mathrm{s}$ to $26.1 \%$ $\mathrm{w} / \mathrm{s}$, for 19 augerings, and from $10.0 \% \mathrm{w} / \mathrm{s}$ to $28.3 \% \mathrm{w} / \mathrm{s}$ for the maximum depth (Wadrill) of the 31 augerings (Table 2). The means for Wa100 and Wadrill were 18.0\% w/s and 17.1\% w/s, respectively, and they were not significantly different $(\mathrm{p}>0.05)$. The discrepancies between Wa100 and Wadrill for the 19 soils having both determinations were $\leq 3.3 \% \mathrm{w} / \mathrm{s}$. These discrepancies are allowable considering the accuracy of the Wa determinations. Accordingly, the Wadrill values can be used when needed as surrogates of Wa100. The set of 31 values formed by the nineteen Wa100 values, plus the twelve surrogated Wadrill values from the augerings shallower than $100 \mathrm{~cm}$, (Table 2) make the attributed actual water content (Waat) data set.

Separate ECe/EMh calibrations for (i) the 31 augerings having Waat (Equation 1), and (ii) for all the 40 augerings (Equation 2), did not show significative differences (Chow test $\mathrm{P}>$ $0.05)$ between them.

$\begin{array}{lllll}\text { ECe } \max =0.40+1.61 \times E M h & \mathrm{R}^{2}=35.8 \% & \mathrm{SE}=0.20 \mathrm{dS} \mathrm{m}^{-1} & \mathrm{n}=31 & \text { Equation 1 } \\ \text { ECe } \max =0.10+2.59 \times \mathrm{EMh} & \mathrm{R}^{2}=56.4 \% & \mathrm{SE}=0.36 \mathrm{dS} \mathrm{m}^{-1} & \mathrm{n}=40 & \text { Equation 2 }\end{array}$

All 40 sampled sites were considered within an acceptable range of soil moisture for EM38 calibration.

A better adjustment (Equation 3) was attained by excluding twelve sites (nos. 5, 34, 40, $66,67,68,69,75,77,79,81$, and 84 ) from the 31 points, where augering was shallower than 1 $\mathrm{m}$, i.e., the value of ECe does not account for layers with relevant contribution to EMI readings.

$$
\text { ECe } \max =0.06+2.32 \times \mathrm{EMh}^{2}=73.0 \% \quad \mathrm{SE}=0.31 \mathrm{dS} \mathrm{m}^{-1} \mathrm{n}=19 \quad \text { Equation } 3
$$

\subsection{Local variability of soil salinity and its effects on EMI readings and calibrations}

The variability of the five uncorrected EMI readings associated with each augering is shown in Figure 7. The variability of the five EMI readings $(\mathrm{C}, \mathrm{N}, \mathrm{S}, \mathrm{E}, \mathrm{W})$ increases as the reading increases. Field notes for site 66 indicate "saline patch", which agrees with the variability of the five readings that were much higher than expected from the ranking of site 66 on the horizontal axis in Figure 7, i.e., the EMH and EMV readings at point C.

The EM38 model used in our survey had a three dial with scales 0-30, 30-100, and 100300 , respectively for the analog reading of the signal from the receiving coil. The differences 
between the five uncorrected readings from each augering are imperceptible from the 0-30 scale, while those from the 30-100 scale are much greater, and those from the 100-300 scale they are easily perceptible (Figure 7), even though the few sites had readings within range. It is difficult to assess whether the EMI readings are influenced by the change of scale, or if they show only the classical feature of higher spatial variability within the more saline soils. The question could be statistically analyzed if additional nested EMI reading sites had EMH or EMV within both the 0-30, and the 30-100 scales, i.e. for sites highly saline.

Log transformed EMh C, N, E, S, and W readings were normally distributed (ShapiroWilk test, $\mathrm{P}>0.05)$ and free of outliers. The Levene's test results confirmed homogeneous error variance of EMh at five data points. The analysis of variance of EMh at $\mathrm{C}, \mathrm{N}, \mathrm{E}, \mathrm{S}$, and $\mathrm{W}$ points showed no significant $(\mathrm{P}>0.05)$ difference. This similarity confers high reliability to the EMh readings at the central point $(\mathrm{C})$ for each site. Moreover, it enables one to assign a single reading $(\mathrm{C})$ to a circle of at least $2-\mathrm{m}$ radius. This radius illustrates the allowable tolerance for the location of the sampling points of the surveys for multi temporal comparison of soil salinity from similar sites of this irrigation district. Moreover, a soil surface with the same EMh response enables the intentional displacement of future sampling points from their previous GPS locations to avoid artifacts that remain in the soil. This tolerance is useful with the spatial resolution of commercial GPS. However, it could probably be larger and variable from plot to plot as suggested by EMI studies from other irrigated plots of this district (Díaz and Herrero, 1992; Herrero et al., 2003).

ECe and EMh data were random (Durbin Watson test) and ECe100 was fit into a linear model with all the five (C, N, E, S, and W) EMh data. Log transformation of ECe100 failed to correct both the non normality and constant variance of ECe100/EMh regression residuals. However, Box-Cox transformation satisfied the residual normal distribution, but violated the constant residual variance assumption. Both ECe and EMI readings were much greater at sampling site 15 than for the other sites (Table 2). Moreover, ECe exceeds $10 \mathrm{dS} \mathrm{m}^{-1}$, the upper limit of the EM38 (McNeill, 1980). In order to check if the site 15, which is shown as a XY outlier in scatter plot (Figure 8), distorts the regression, Box-Cox transformed ECe100 was calibrated with and without site 15, using ordinary least squares method resulting Equations 4 and 5 .

$$
\begin{array}{lllll}
\text { ECe100 }=1.26-0.68 \times \text { EMh } & \mathrm{R}^{2}=47.1 \% & \mathrm{n}=27 & (\text { with point 15) } & \text { Equation } 4 \\
\text { ECe100 }=1.39-1.00 \times \mathrm{EMh} & \mathrm{R}^{2}=68.0 \% & \mathrm{n}=26 & (\text { without point 15) } & \text { Equation 5 }
\end{array}
$$


Regression parameters of the two equations were different, indicating a potential influence of point 15 , even that the negative value of slope is physically meaningless after the Box-Cox transformation. Removal of point 15 proposed a better fit for the linear model with a higher $\mathrm{R}^{2}$ value $(68.0 \%$ vs $47.1 \%)$. Standardized residual plot of Box-Cox transformed regression, Cook's D and Dfbetas values indicated that point 15 along with points $6,17,76$, and 1015 can be potentially influential (Figure 9).

OLS and LTS regression of ECe100 on EMh readings for $\mathrm{C}, \mathrm{N}, \mathrm{E}, \mathrm{S}$, and $\mathrm{W}$ points yielded the ten equations shown in Table 3. All the five regression lines had significant coefficients of determination, which indicate strong linear relationships between two variables. As expected, point $\mathrm{C}$ yields the highest coefficient of determination and a relatively low standard error. Chow test for equal regression parameters showed no significant difference ( $p>$ 0.05 ) between any pair of the five regression lines. Thus, any one of the five points can be used for calibration.

Depending upon whether we deem OLS or LTS method more appropriated, as discussed later, we can use the equations:

$$
\begin{array}{lllll}
\text { ECe100 }=-1.99+8.00 \times \mathrm{EMh} & \mathrm{R}^{2}=94.5 \% & \mathrm{SE}=1.00 \mathrm{dS} \mathrm{m}^{-1} & \mathrm{n}=27 & \text { Equation 6 } \\
\text { ECe100 }=-0.20+3.21 \times \mathrm{EMh} & \mathrm{R}^{2}=68.7 \% & \mathrm{SE}=0.49 \mathrm{dS} \mathrm{m}^{-1} & \mathrm{n}=27 & \text { Equation 7 }
\end{array}
$$
to calibrate for 1999 .

These equations were calculated with EMh that ranged from 0.25 to 2.68.

\subsection{EM38 calibration for different soil depths}

Table 4 shows the regression equations of ECe on EMh and EMv for 20, 40, 60, 80, 100 , and $150 \mathrm{~cm}$ depth. The maximum coefficients of determination for LTS calibration are reached using the $100 \mathrm{~cm}$ depth for EMh and the $150 \mathrm{~cm}$ depth for EMv. These results are consistent with the curves of relative contribution of the different soil layers to the readings of EM38 in the horizontal and vertical orientations (McNeill, 1992) and with the most frequent vertical salinity distribution (Figure 6) along the computed depths of the profiles from the regressions of this study. For the vertical distribution, the most common departures from the general shape occur in surface layers, some of them much more saline than the average ECe100. This seems logical because all auger holes were made a few days after irrigation during the same month. A departure from this conclusion, as denoted mostly by the outliers in Figure 6, occurs within only a few profiles and the effect on calibrations is moderate. 
The regression line for ECe150 calibration with EMv was significantly different (Chow test $\mathrm{P}<0.05)$ from the line of ECe100 calibration with EMh (Table 4). Except for the $80 \mathrm{~cm}$ depth, the calibration for ECe150 is the only one with coefficient of determination better for EMv than EMh $\left(\mathrm{R}^{2}: 75.5 \%\right.$ vs $\left.62.1 \%\right)$, which is the result of the limit of the response curves EM38 (McNeill, 1992). Therefore, we chose to use ECe100 for calibration.

Figure 8 shows the regression lines obtained by OLS and by LTS methods. It is inappropriate to use LTS equation to predict all the ECe100 values, because LTS method uses only a subset of all data whose least squares fit possesses the smallest sum of squares residuals. Previous experience in calibrations of EM38 on soils of this area also resulted in a similar performance of OLS method against non-parametric methods (Nogués et al., 2006; Herrero et al., 2007), in spite of the violations of some statistical assumptions of OLS method. In our case (Figure 8), we could imagine a proposal of discarding observations with low EMI readings if we gathered a sufficient number of high EMI readings for a separate calibration. In most cases, the non saline soils are not the target of EMI calibrations. However, the proposal of a threshold is very arguable because the variability of soil temperature and moisture strongly influences the EMI response. Moreover, such as threshold can in no way be generalized for other irrigated districts. For the above reasons, the easy and popular OLS method is recommended.

\subsection{EM38 calibration for salinity-prone sites}

Plots or map units with no symptoms of salinity could be discarded for monitoring to concentrate our efforts on salt-affected areas. An EM38 calibration was assayed for the 27 sites where augering reached $100 \mathrm{~cm}$ depth. These 27 sites consisted of 20 salinity prone sites i.e., having ECe $\geq 2 \mathrm{dS} \mathrm{m}^{-1}$ sometime during the three years of surveying, and 7 non-saline sites as above defined were not included in this analysis. We regressed, with OLS method, ECe100 on EMh for these sites, obtaining:

$$
\mathrm{ECe} 100=-2.07+8.09 \times \mathrm{EMh} \quad \mathrm{R}^{2}=94.7 \% \quad \mathrm{SE}=1.10 \mathrm{dS} \mathrm{m}^{-1} \mathrm{n}=20 \quad \text { Equation } 8
$$

We performed analysis of covariance (ANACOVA) multiple regression with EMh as the continuous variable and the salinity status of sites as the categorical or dummy variable. This model assessed the effect of salinity status on ECe100 values, which controls the effects of EMh. The test results of between-subject effects revealed that salinity status had no significant effect (GLM F test; $p>0.05$ ) on ECe100/EMh relationship. We prefer Equation 6 obtained from all $27 \mathrm{EMh}$ readings because it does not require historical data, soil maps, or 
expert knowledge to determine if each of the studied soils is or is not saline. This criterion can be checked if future monitoring campaigns yield more sites with high salinity.

\subsection{Calibrations for sites grouped by soil map units}

The landscape position of the soil is a key factor for salt distribution. Therefore differentiated soil salinity patterns can occur, which affect EMI calibrations. We grouped sites by soil delineation from the map of Nogués (1994) according to their GPS coordinates. Given the scale of the map, this procedure could have yield some erroneous attribution either because of the map scale, or because the site is located in some soil inclusion not recognized by the soil surveyor. If a more detailed soil map was produced, the attribution to a particular soil map unit of some profiles could change.

We calculated calibration equations for the soil map units by grouping them into two categories: non saline mesas -Unit A-(Equation 9), and all the other, more or less saline, units (Units B.1, B.2.1, C, and D) together (Equation 10). We used ECe100 plus ECemaxd as the dependent variable and regressed with EMh, which resulted Equations 9 and 10.

$$
\begin{array}{lllll}
\mathrm{ECe}=0.39+1.83 \times \mathrm{EMh} & \mathrm{R}^{2}=43.1 \% & \mathrm{SE}=0.21 \mathrm{dS} \mathrm{m}^{-1} \mathrm{n}=13 & \text { Equation 9 } \\
\mathrm{ECe}=-1.97+8.02 \times \mathrm{EMh} & \mathrm{R}^{2}=67.5 \% & \mathrm{SE}=0.32 \mathrm{dS} \mathrm{m}^{-1} & \mathrm{n}=27 & \text { Equation 10 }
\end{array}
$$

The relationships between ECe and EMh are different between the two soil unit types. The two equations are coherent and their coefficients of determination agree with the characteristics of the soils within each soil unit type. Soil mapping units designated as B.1, B.2.1, C, and D had a better coefficient of determination $\left(\mathrm{R}^{2}=67.5 \%\right)$, while non-saline Unit A had a poor calibration $\left(\mathrm{R}^{2}=43.1 \%\right)$. Saline soils had a relatively high standard error value, which reflects the high variability of salinity between the groups. Units B.2.1 and D had relatively good calibrations with $\mathrm{R}^{2}$ ranging from $88.9 \%$ to $90.5 \%$ (Equations 11 and12).

$$
\begin{array}{lllll}
\mathrm{ECe}=0.04+2.18 \times \mathrm{EMh} & \mathrm{R}^{2}=90.5 \% & \mathrm{SE}=0.84 \mathrm{dS} \mathrm{m}^{-1} & \mathrm{n}=8 & \text { Equation } 11 \\
\mathrm{ECe}=-0.68+6.77 \times \mathrm{EMh} & \mathrm{R}^{2}=88.9 \% & \mathrm{SE}=0.86 \mathrm{dS} \mathrm{m}^{-1} & \mathrm{n}=7 & \text { Equation } 12
\end{array}
$$

The poor calibration obtained for Unit A (Equation 9) could be related to the moisture content at the time of the EMI survey. Soils in Unit A were dryer than all the other units, and with higher irregularity in the moisture profiles. In order to evaluate the influence of Wa, we assayed a separate calibration for sites $34,50,61,71,81$, and 84 , from Unit A, and whose the Wa to water holding capacity ratio was similar to the other units. For this purpose, we used ECe, i.e., ECe100 and ECemaxd (Table 2) to obtain Equation 13, by OLS method:

$$
\mathrm{ECe}=0.13+2.36 \times \mathrm{EMh} \quad \mathrm{R}^{2}=78.0 \% \quad \mathrm{SE}=0.09 \mathrm{dS} \mathrm{m}^{-1} \quad \mathrm{n}=6 \quad \text { Equation } 13
$$


The coefficient of determination is much higher than the $\mathrm{R}^{2}=43.1 \%$ obtained when calibrated using the 13 Unit A sites (Equation 9). This shows the importance of calibrating at adequate and homogeneous moisture content. The heterogeneity of Wa in the soils of Unit $\mathrm{A}$ is related to their low available water holding capacity and variable stoniness. The need of available water holding capacity and Wa determination for each profile for EM38 calibration would negate the practical utility of the EMI readings on this soil unit. For Unit A, Wa was inconsequential for salinity monitoring because this soil unit is not saline and does not have a salinization risk.

The other soil units have both saline and non-saline soils, as established in the definitions of the soil associations used as map units by Nogués (1994). Thus, a more detailed soil map would be needed to discard the non-saline and the non salinity-prone plots from the EMI survey.

475 The EM38 can be calibrated for more or less saline soil units using Equations 9 to 13. ANACOVA regression that used soil map unit type (Unit A vs. all other units together) as a dummy variable indicate no significant effect (GLM F test $\mathrm{P}>0.05)$ of soil map unit type on the ECemaxd/EMh relationship. The good calibration obtained with all studied sites (ECe100/EMh, Tables 3 and 4) supports our proposal of a single calibration for all units. New calibrations will be needed for future EMI surveys, as is the case for individual plots monitoring (López-Bruna and Herrero, 1996). This requirement will be permanent because the calibration area is an irrigated district with thousands of plots under different management. Thus, it is very improbable for the salinity to proportionally change temporally, a condition required (Lesch et al., 1998) to maintain the calibration equations between two sampling dates.

\subsection{When to take EMI readings?}

An important question is how to determine if the field soil moisture is adequate for EMI reading without taking soil samples or using special devices, a procedure which would lessen the advantages of an EMI survey. The rule of reading a couple of days after irrigation (López490 Bruna and Herrero, 1996) from a plot is unsuitable for irrigation districts because of the lack of quick communication between the scientist and the irrigators. A practical upper threshold for moisture can be whether water is ponded or the plot surface is muddy. The lower threshold for moisture is difficult to establish for the field with only visual or feel appraisals of the soil's surface moisture, which can be checked with observations from other plots where the time elapsed from the last irrigation is known. This standard procedure based on irrigation can not 
be substituted by waiting for a heavy rain because rains are scarce in Flumen as in many other irrigated districts. Most rains are a result of thunderstorms with irregular geographical coverage. Homogeneous soil moisture for entire the irrigation district is not reached, which was the case for the 1999 sampling. This has been a common situation for most years over three decades of field activities throughout irrigation districts of the central Ebro valley.

The development of a rigorous monitoring program is not trivial because soil salinity is a dynamic process. The soil solution salinity (ECe) is the property of interest, but EMI readings are also dependent on water content and soil temperature. Soil temperature corrections are easy, but water content is difficult. Monitoring for the long term depends on having some knowledge of water content at the time of monitoring. This is the main reason for calibrations for successive years, and then to check that water content did not affect calibration for "our" year.

\section{Conclusions}

After calibration using a modest number of sites from the Flumen irrigation district, EMI is a potential method to estimate and map soil salinity regardless that the soil is heterogeneous, both in composition and moisture, and the lack of a statistical design of the measuring-site locations. These facts plus our previous experience in this district, indicates EMI can be an effective tool for future salinity assessments.

The soil augering limited to $1 \mathrm{~m}$ depth can be recommended. The practical results of ordinary least squares calibration, even if not meeting all statistical assumptions, are sounder than the least trimmed squares method.

Field estimation of the soil moisture adequacy for EMI readings was sufficient for 1999, as shown by the calibrations obtained and by the measures of the actual soil moisture and their comparison with the interval of water retention from $-33 \mathrm{kPa}$ to $-1500 \mathrm{kPa}$. The recommendation of conducting EMI surveys a few days after irrigation still holds. However, for most irrigation districts, the irrigation dates are unknown; therefore, expert knowledge helped by visual and feel observations has to be used to appraise the soil moisture.

A tolerance of at least two meters around previous destructive soil samplings is allowable for further samplings in order to avoid inherited salinity artifacts. This tolerance needs detailed further investigation with different distances of EMI readings and soil sampling. Attention should be given to highly saline sites to determine if intensive EMI readings or soil samplings are needed. Detailed soil maps and further application of geostatistical techniques 
hopefully will improve our findings. The possible effects of the dials and their scales used to calibrate the EMI instrument needs to be investigated.

Mesas cannot be discarded during future EMI surveys for salinity assessment of the studied irrigation district. All the soil units irrespective of the actual or potential soil salinity need to be included. The data gathered in the present work can serve as a baseline even if new sampling strategies are set up for future surveys. The use of EMI must take into account the representativity of the readings. EMI values obtained during our EMI survey represent at least a circle with a 2-m radius. This area could be larger or smaller for different soil units if other sets of EMI readings at several distances from the central reading point were acquired or if geostatistical studies were undertaken to determine semivariograms. Knowledge of size of the area represented by an EMI reading will enable the placement of future readings or samplings within the area, without loosening the relationship with the initial observation. If some of the previous observations were destructive, the forthcoming EMI readings or augerings can be displaced from the initial position located with GPS or other geodetic procedures, in order to avoid inherited soil salinity distribution artifacts.

The good calibrations of the EM38 obtained during 1999 endorse future intense use of EMI instruments, with simultaneous soil samplings to reduce the number of sites needed to validate the EMI values. This optimises the opportunity to apply geostatistical techniques to EMI surveys and related soil sampling needed to validate the EMI data.

To understand soil salinity evolution requires monitoring of other characteristics such as crops, irrigation doses, agricultural practices, irrigation and drainage networks, and etc. This will allow others to identify research needs, and to formulate guidelines for soil salinity management, an issue closely linked to water management. The issues discussed in this article, calibration, effect of dial change, and the "localization paradox", are relevant for saline irrigated districts around the world as well as for soil monitoring of variable properties other than salinity.

Acknowledgements. Field and laboratory works were done at the Soils and Irrigation Unit, Zaragoza, Spain. This article was completed thanks to the funds of the Spanish projects GALC-006-2008, PIE-CSIC 200840I246, and AGL2009-08931/AGR.

\section{References}


Amezketa, E., 2006. An integrated methodology for assessing soil salinization, a pre-condition for land desertification. Journal of Arid Environments 67, 594-606.

Box, G.E.P., Cox, D.R., 1964. An analysis of transformation. Journal of the Royal Statistical Society, series B, 26, 211-243.

Chambers, J.M., Cleveland, W.S., Kleiner, B., Tukey, P.A., 1983. Graphical methods for data analysis. Chapman and Hall. New York, NY.

Chow, G., 1960. Tests of equality between sets of coefficients in two linear regressions. Econometrica 28, 591-605.

Corwin, D.L., Plant, R.E., 2005. Applications of apparent soil electrical conductivity in precision agriculture. Computers and Electronics in Agriculture 46, 1-10.

De Clerck, F., Singer, M.J., Lindert, P., 2003. A 60-year history of California soil quality using paired samples. Geoderma 114, 215-230.

Derici, M.R., 2002. Degradation, chemical. Pp. 268-279 in R. Lal (Ed.) Encyclopedia of Soil Science. Marcel Dekker Inc., New York, NY.

Díaz, L., Herrero, J., 1992. Salinity estimates in irrigated soils using electromagnetic induction. Soil Science 154, 151-157.

Ghassemi, F.A., Jakeman, A.J., Nix, H.A., 1995. Salinization of land and water resources: Human causes, extent, management, and case studies. CAB International, $526 \mathrm{pp}$.

Herrero, J., 1987. Tendencias de salinidad en suelos del sistema de riegos Monegros-Flumen. $7^{\mathrm{a}}$ Conferencia sobre Hidrología General y Aplicada, SMAGUA: 411-421. Zaragoza, Spain.

Herrero, J., 2008. La salinidad edáfica en varios salobrares de Aragón. Memorias de la Real Sociedad Española de Historia Natural 4, 1-164.

Herrero, J., Pérez-Coveta, O., 2005. Soil salinity changes over 24 years in a Mediterranean irrigated district. Geoderma 125, 287-308.

Herrero, J., Ba, A.A., Aragüés, R., 2003. Soil salinity and its distribution determined by soil sampling and electromagnetic techniques. Soil Use and Management 19, 119-126.

Herrero, J., Robinson, D.A., Nogués, J., 2007. A regional soil survey approach for upgrading from flood to sprinkler irrigation in a semi-arid environment. Agricultural Water Management 93, 145-152.

Hettmansperger, T.P., Sheather, S.J., 1986. Confidence intervals based on interpolated order statistics. Statistics and Probability Letters 4, 75-79.

IRYDA, 1975. Estudio de suelos de la $1^{\mathrm{a}}$ y $2^{\mathrm{a}}$ partes de la zona regable de Flumen (Huesca). Instituto Nacional de Reforma y Desarrollo Agrario. Minist. Agricultura. Madrid, Spain. 
Lesch, S.M., 2005. Sensor-directed response surface sampling designs for characterizing spatial variation in soil profiles. Computers and Electronics in Agriculture 46, 153-179.

Lesch, S.M., Herrero, J., Rhoades, J.D., 1998. Testing for changes in field salinity levels over time using electromagnetic induction techniques. Soil Sci. Soc. Am. J. 62, 232-242.

López-Bruna, D., Herrero, J., 1996. El comportamiento del sensor electromagnético y su calibración frente a la salinidad edáfica. Agronomie 16, 95-105.

Martínez Cob, A., Faci, J.M., Bercero, A., 1998. Evapotranspiración y necesidades de riego de los principales cultivos en las comarcas de Aragón. Inst. Fernando el Católico. Zaragoza, Spain.

McNeill, J.D., 1980. Survey interpretation techniques EM38. Technical Note No. 6, Geonics Ltd. Ontario, Canada.

McNeill, J.D., 1992. Rapid, accurate mapping of soil salinity using electromagnetic ground conductivity meters. pp. 209-229, In: G.C. Topp, W.D. Reynolds, R.E. Green (Eds.), Advances in measurement of soil physical properties: bringing theory into practice. SSSA Special Publication No. 30. Madison, WI.

Nogués, J., 1994. Evaluación de tierras mediante la aplicación del método FAO 1976 y su integración en un sistema de información territorial en las 26000 ha (sectores IV al XI) regadas por el canal del Flumen. Proyecto Final de Carrera. University of Lérida, Spain.

Nogués, J., Robinson, D.A., Herrero, J., 2006. Incorporating electromagnetic induction methods into regional soil salinity survey of irrigation districts. Soil Sci. Soc. Am. J. 70, 2075-2085.

Rhoades, J.D., Chanduvi, F., Lesch, S.M., 1999. Soil salinity assessment. Methods and interpretation of electrical conductivity measurements. FAO Irrigation and Drainage Paper 57. FAO, Rome, Italy.

Rousseew, P.J., Leroy, M., 1987. Robust regression and outlier detection. John Wiley \& Sons, New York.

Sumner, M., Naidu, R., 1998. Sodic soils: distribution, properties, management, and environmental consequences. Oxford University Press, New York.

Tukey, J.W., 1977. Exploratory data analysis. Addison-Wesley, Mass.

Young, A., 1998. Land resources now and for the future. Cambridge University Press, Cambridge, UK.

United States Salinity Laboratory Staff, 1954. Diagnosis and improvement of saline and alkali soils. Agriculture Handbook 60. USDA. Reprint. 1969. 
Table 1. Quantitative assessment of soil salinity in the geomorphic units mapped by Nogués (1994).

\begin{tabular}{cll}
\hline Symbol in the map & \multicolumn{1}{c}{ Map unit } & Salinity \\
\hline A & Mesas & Non saline \\
B. 1 & Piedmont slopes & Moderate \\
B. 2.1 & Other slopes & From slight to moderate \\
C & River terraces & From nil to strong \\
D & Bottoms & From moderate to strong \\
\hline
\end{tabular}


Table 2. Depth and ECe up to $100 \mathrm{~cm}$ depth (ECe100) or up the maximum auger 630 depth, EM38 readings (EMh and EMv), and percent of actual gravimetric moisture content up to $100 \mathrm{~cm}$ (Wa100) and up to the total depth drilled (Wadrill). Salinity prone plots (i.e., ECe $\geq 2 \mathrm{dS} \mathrm{m}^{-1}$ in 1975, 1985 or 1999) are marked with 1 in the last column.

\begin{tabular}{|c|c|c|c|c|c|c|c|c|c|}
\hline Site & $\begin{array}{l}\text { Soil unit } \\
\text { (Nogués, } \\
\text { 1994) }\end{array}$ & $\begin{array}{l}\text { Augering } \\
\text { depth, } \\
\text { cm }\end{array}$ & $\begin{array}{c}\text { ECe100, } \\
\text { dS m }{ }^{-1}\end{array}$ & $\begin{array}{c}\text { ECemaxd } \\
\text { dS m }^{-1}\end{array}$ & EMh & EMv & $\begin{array}{l}\text { Wa100, } \\
\% \text { w/s }\end{array}$ & $\begin{array}{c}\text { Wadrill, } \\
\% \text { w/s }\end{array}$ & $\begin{array}{c}\text { Salinity } \\
\text { prone }\end{array}$ \\
\hline 5 & B.2.1. & 85 & & 4.05 & 0.75 & 0.67 & & 23.60 & 1 \\
\hline 6 & $\mathrm{D}$ & 165 & 2.88 & & 0.33 & 0.44 & & & 1 \\
\hline 8 & A & 62 & & 5.50 & 0.40 & 0.49 & & & 1 \\
\hline 9 & $\mathrm{D}$ & 150 & 0.95 & & 0.47 & 0.58 & 20.24 & 20.97 & 1 \\
\hline 10 & $\mathrm{D}$ & 150 & 4.13 & & 0.73 & 1.04 & & & 1 \\
\hline $11 \mathrm{~b}$ & B.2.1. & 150 & 2.50 & & 0.59 & 0.59 & & & 1 \\
\hline 13 & $\mathrm{D}$ & 136 & 6.54 & & 1.02 & 1.25 & & & 1 \\
\hline 15 & B.1. & 134 & 20.34 & & 2.68 & 2.48 & & & 1 \\
\hline 17 & B.1. & 141 & 6.77 & & 0.87 & 0.79 & 19.78 & 17.16 & 1 \\
\hline 25 & $\mathrm{C}$ & 149 & 1.08 & & 0.43 & 0.48 & & & 0 \\
\hline 26 & $\mathrm{D}$ & 152 & 0.90 & & 0.34 & 0.38 & 15.96 & 15.35 & 1 \\
\hline 27 & B.1. & 160 & 0.66 & & 0.46 & 0.44 & & & 0 \\
\hline 28 & B.1. & 168 & 0.53 & & 0.30 & 0.31 & 21.87 & 21.41 & 0 \\
\hline 31 & $\mathrm{C}$ & 142 & 0.89 & & 0.41 & 0.48 & 26.07 & 28.26 & 1 \\
\hline 34 & A & 65 & & 0.74 & 0.24 & 0.19 & & 14.57 & 0 \\
\hline 35 & B.1. & 130 & 0.68 & & 0.29 & 0.24 & 15.52 & 14.47 & 1 \\
\hline 40 & B.2.1. & 71 & & 0.72 & 0.39 & 0.42 & & 16.20 & 0 \\
\hline 41 & A & 105 & 1.42 & & 0.29 & 0.32 & 14.46 & 14.07 & 0 \\
\hline 50 & A & 126 & 1.12 & & 0.40 & 0.50 & 13.00 & 14.54 & 0 \\
\hline 51 & B.2.1. & 150 & 1.09 & & 0.43 & 0.53 & 17.60 & 18.29 & 1 \\
\hline 56 & B.2.1. & 125 & 0.75 & & 0.33 & 0.38 & 17.23 & 17.53 & 1 \\
\hline 57 & $\mathrm{D}$ & 120 & 8.52 & & 1.38 & 1.44 & 20.92 & 21.49 & 1 \\
\hline 58 & $\mathrm{C}$ & 140 & 1.77 & & 0.61 & 0.66 & 19.46 & 19.96 & 1 \\
\hline 59 & B.1. & 152 & 1.49 & & 0.48 & 0.55 & & & 1 \\
\hline 61 & A & 149 & 0.66 & & 0.25 & 0.25 & 14.50 & 13.87 & 0 \\
\hline 62 & B.1. & 162 & 0.80 & & 0.25 & 0.25 & 12.80 & 15.80 & 1 \\
\hline 65 & B.1. & 170 & 0.91 & & 0.27 & 0.34 & 19.79 & 23.10 & 1 \\
\hline 66 & $\mathrm{D}$ & 90 & & 4.51 & 0.60 & 0.80 & & 19.76 & 1 \\
\hline 67 & A & 98 & & 1.15 & 0.23 & 0.23 & & 12.79 & 0 \\
\hline 68 & A & 20 & & 0.85 & 0.11 & 0.07 & & 11.35 & 0 \\
\hline 69 & B.2.1. & 61 & & 0.87 & 0.18 & 0.18 & & 15.15 & 0 \\
\hline 71 & A & 157 & 0.71 & & 0.30 & 0.24 & 15.88 & 15.77 & 0 \\
\hline 75 & A & 70 & & 1.30 & 0.35 & 0.38 & & 10.04 & 1 \\
\hline 76 & $\mathrm{C}$ & 140 & 2.84 & & 0.84 & 0.97 & 20.49 & 20.45 & 1 \\
\hline 77 & A & 50 & & 0.64 & 0.21 & 0.19 & & 13.12 & 0 \\
\hline 79 & $\mathrm{~A}$ & 36 & & 0.52 & 0.11 & 0.11 & & 12.24 & 0 \\
\hline 81 & A & 64 & & 0.63 & 0.23 & 0.26 & & 17.47 & 0 \\
\hline 84 & A & 55 & & 0.77 & 0.23 & 0.26 & & 15.24 & 0 \\
\hline 1015S1 & B.2.1. & 100 & 0.97 & & 0.42 & 0.42 & 18.87 & 18.87 & 1 \\
\hline 1015S2 & B.2.1. & 100 & 1.60 & & 0.71 & 0.80 & 17.78 & 17.78 & 1 \\
\hline $\bar{n}$ & 40 & 40 & 27 & 13 & 40 & 40 & 19 & 31 & 40 \\
\hline
\end{tabular}


Table 3. ECe100 relationship with the EMh readings at C, N, E, S, and W points (ECe $100=a+b \times \mathrm{EMh}$ ), calculated by ordinary least squares estimation and by least trimmed squares.

\begin{tabular}{|c|c|c|c|c|c|c|c|c|c|}
\hline \multirow{2}{*}{$\begin{array}{c}\text { Point } \\
\text { location }\end{array}$} & \multirow{2}{*}{$\begin{array}{c}\text { Number } \\
\text { of sites }\end{array}$} & \multicolumn{4}{|c|}{ Ordinary least squares } & \multicolumn{4}{|c|}{ Least trimmed squares } \\
\hline & & $\boldsymbol{a}$ & $\boldsymbol{b}$ & $\mathbf{R}^{2}$ & $\begin{array}{c}\mathrm{SE} \\
\mathrm{dS} \mathbf{~ m}^{-1}\end{array}$ & $\boldsymbol{a}$ & $\boldsymbol{b}$ & $\mathbf{R}^{2}$ & $\begin{array}{c}\text { SE } \\
\text { dS m } \text { m }^{-1}\end{array}$ \\
\hline $\mathrm{C}$ & 27 & -1.99 & 8.00 & 94.5 & 1.0 & -0.20 & 3.21 & 68.7 & 0.49 \\
\hline $\mathrm{N}$ & 27 & -2.16 & 8.23 & 88.6 & 1.4 & 0.13 & 2.37 & 49.6 & 0.54 \\
\hline $\mathrm{E}$ & 27 & -1.94 & 7.65 & 92.1 & 1.2 & -0.00 & 2.68 & 65.7 & 0.44 \\
\hline $\mathrm{S}$ & 27 & -2.76 & 9.61 & 91.0 & 1.2 & -0.20 & 3.28 & 62.1 & 0.65 \\
\hline W & 26 & -2.15 & 8.30 & 93.3 & 1.1 & -0.64 & 4.17 & 62.5 & 0.44 \\
\hline
\end{tabular}

Significance level for all equations is $p<0.001$

640

Table 4. Calibration, by two methods, of the horizontal (EMh) and vertical (EMv) readings in the central point $(\mathrm{C})$ of each sampling site on ECe weighted up to several depths, considering all sampling sites.

\begin{tabular}{|c|c|c|c|c|c|c|c|c|c|}
\hline \multirow{2}{*}{$\begin{array}{l}\text { Computed } \\
\text { depth }(\mathrm{cm})\end{array}$} & \multirow{3}{*}{$\begin{array}{c}\text { Number } \\
\text { of sites } \\
\text { computed }\end{array}$} & \multicolumn{4}{|c|}{$\mathrm{ECe}=a+b \times \mathbf{E M h}$} & \multicolumn{4}{|c|}{$\mathrm{ECe}=a+b \times \mathbf{E M v}$} \\
\hline & & $a$ & $\boldsymbol{b}$ & $\mathbf{R}^{2}$ & $\begin{array}{c}\text { SE } \\
\text { dS } \mathbf{~ m}^{-1}\end{array}$ & $a$ & $\boldsymbol{b}$ & $\mathbf{R}^{2}$ & $\begin{array}{c}\text { SE } \\
\text { dS m } \mathbf{m}^{-1}\end{array}$ \\
\hline \multicolumn{9}{|c|}{ Ordinary least squares } & \\
\hline 20 & 40 & -3.17 & 12.10 & 80.6 & 2.6 & -3.30 & 11.58 & 72.2 & 3.2 \\
\hline 40 & 38 & -2.41 & 9.76 & 86.5 & 1.7 & -2.64 & 9.48 & 79.1 & 2.1 \\
\hline 60 & 37 & -2.02 & 8.75 & 89.1 & 1.4 & -2.28 & 8.57 & 82.4 & 1.8 \\
\hline 80 & 30 & -2.07 & 8.35 & 93.3 & 1.1 & -2.43 & 8.31 & 87.1 & 1.5 \\
\hline 100 & 27 & -1.99 & 8.00 & 94.5 & 1.0 & -2.38 & 8.03 & 88.8 & 1.4 \\
\hline 150 & 12 & -1.22 & 6.79 & 61.8 & 0.8 & -0.76 & 4.96 & 75.5 & 0.6 \\
\hline \multicolumn{10}{|c|}{ Least trimmed squares } \\
\hline 20 & 40 & 0.13 & 2.60 & 56.0 & 0.40 & 0.27 & 2.04 & 54.1 & 0.32 \\
\hline 40 & 38 & 0.04 & 2.61 & 67.9 & 0.34 & 0.19 & 2.06 & 62.6 & 0.30 \\
\hline 60 & 37 & 0.06 & 2.56 & 66.5 & 0.35 & 0.20 & 2.02 & 61.1 & 0.31 \\
\hline 80 & 30 & -0.57 & 4.81 & 40.7 & 0.96 & -0.32 & 3.63 & 48.3 & 0.63 \\
\hline 100 & 27 & -0.20 & 3.21 & 68.7 & 0.49 & -0.02 & 2.55 & 64.7 & 0.43 \\
\hline 150 & 12 & -1.68 & 7.50 & 62.1 & 0.52 & -0.76 & 4.96 & 75.5 & 0.49 \\
\hline
\end{tabular}

Significance level for all equations is $p<0.001$ 


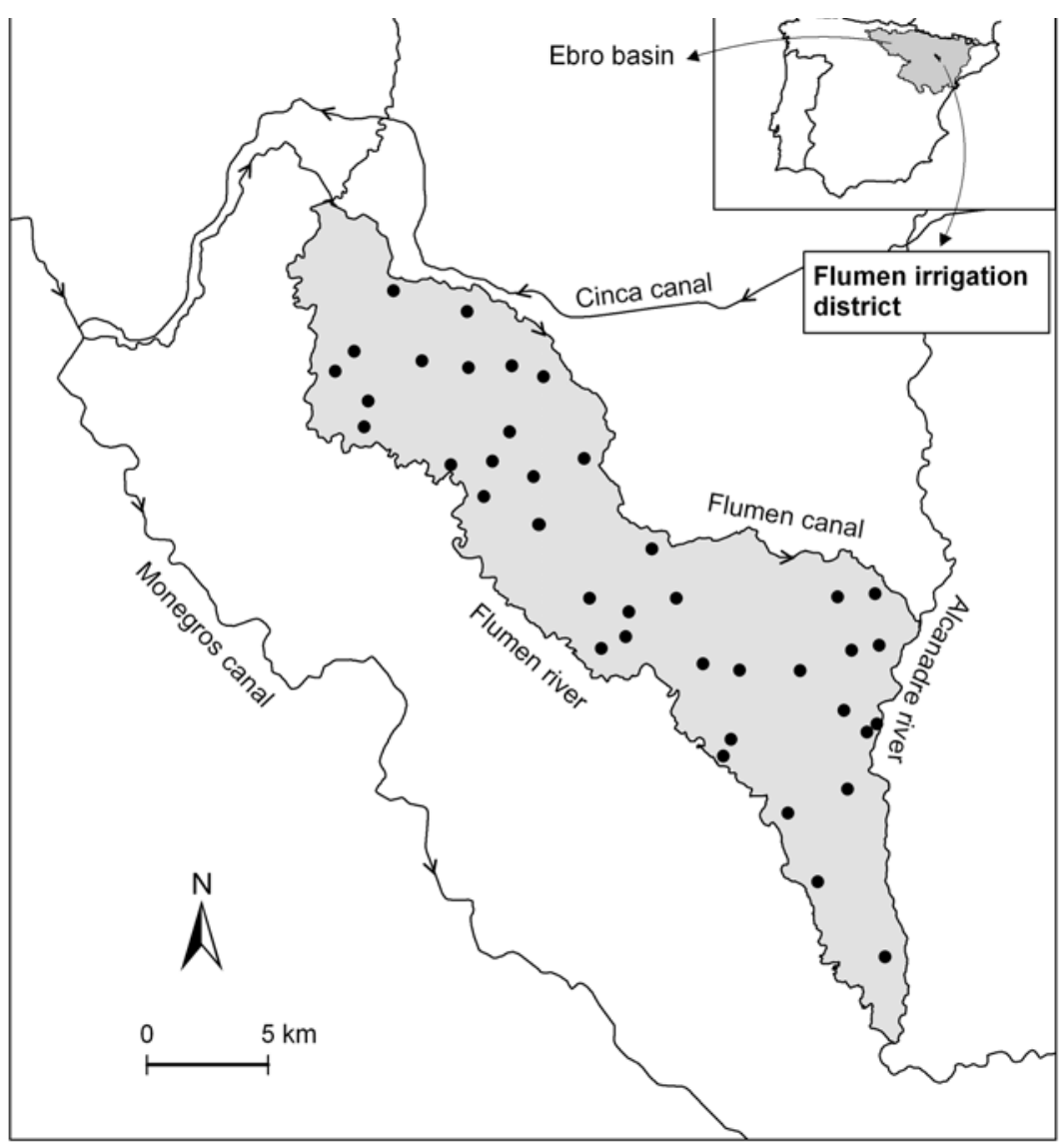

Figure 1. Map of the Flumen irrigation district within the Ebro basin, NE Spain, and location of the sites with soil sampling and electromagnetic induction readings in the studied area (shaded), sectors IV to XI of the district. 


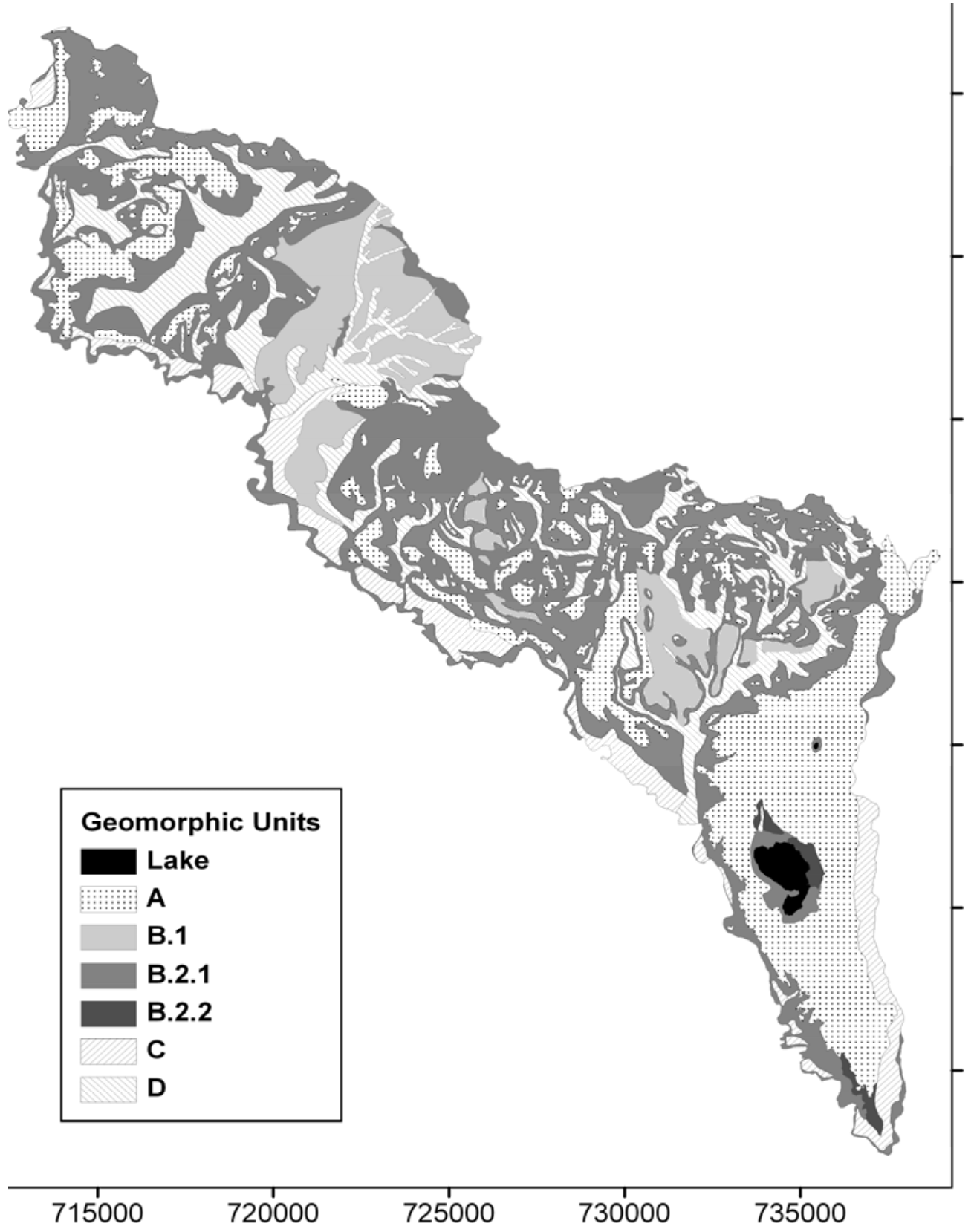

Figure 2. Simplified geomorphic units extracted from the map of Nogués (1994) represented in the Universal Transverse Mercator grid zone 30T. 
Figure 3. Relative disposition of the augering (dashed circle) and the locations of EM38 (rectangles) for the five reading points in both the horizontal and vertical positions of the coils. These locations were: central (C), on the point where the augering is to be made; and at $2 \mathrm{~m}$ from (C) in the four cardinal directions.

Figure 4. Graphical parts of a boxplot.

confidence

the median

lowest value 

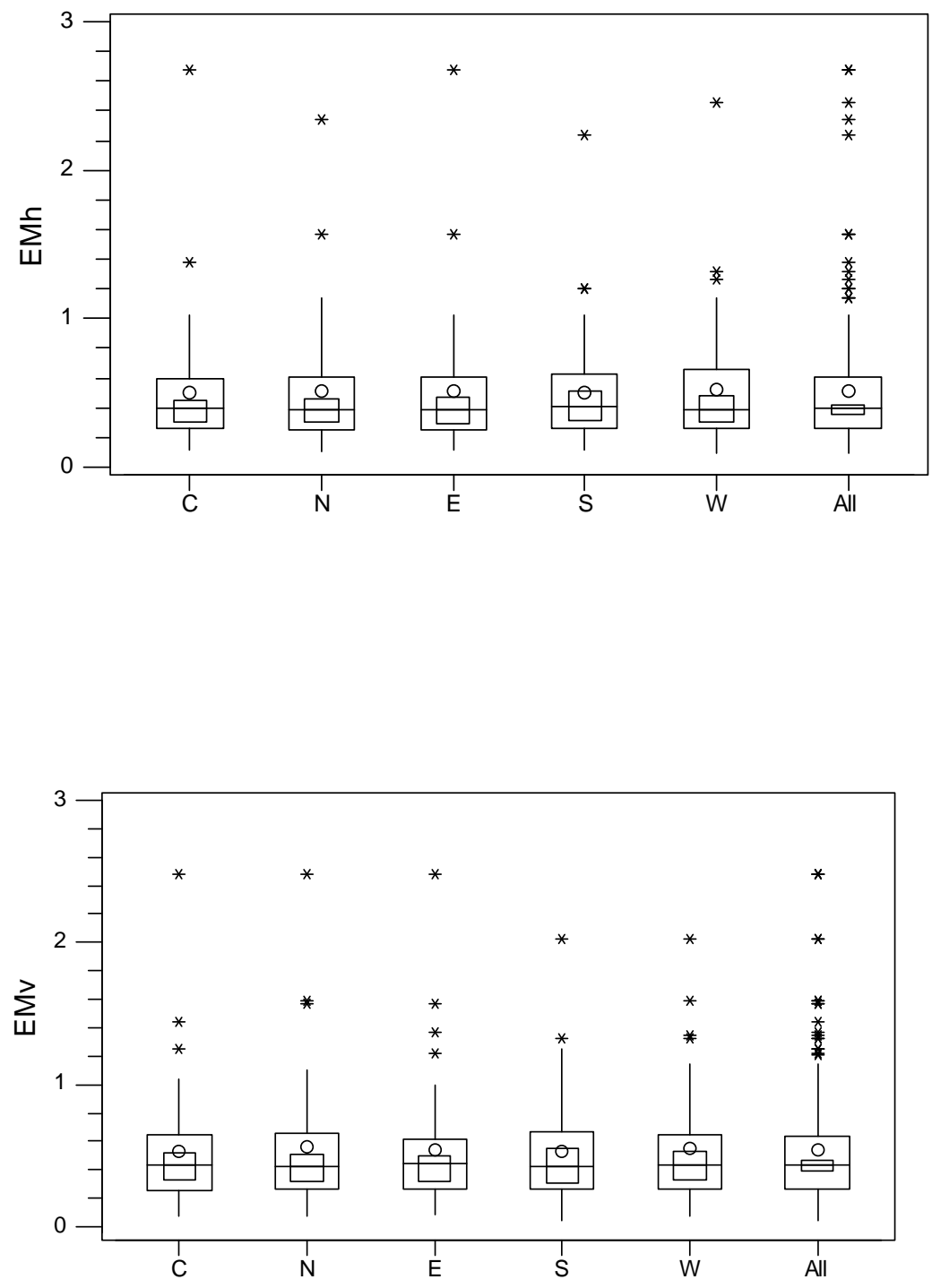

675 Figure 5. Boxplots of EMh and EMv at the augering point (C), at two $\mathrm{m}$ from $\mathrm{C}$ to the North, East, South, and West, and computing the five locations together (All).

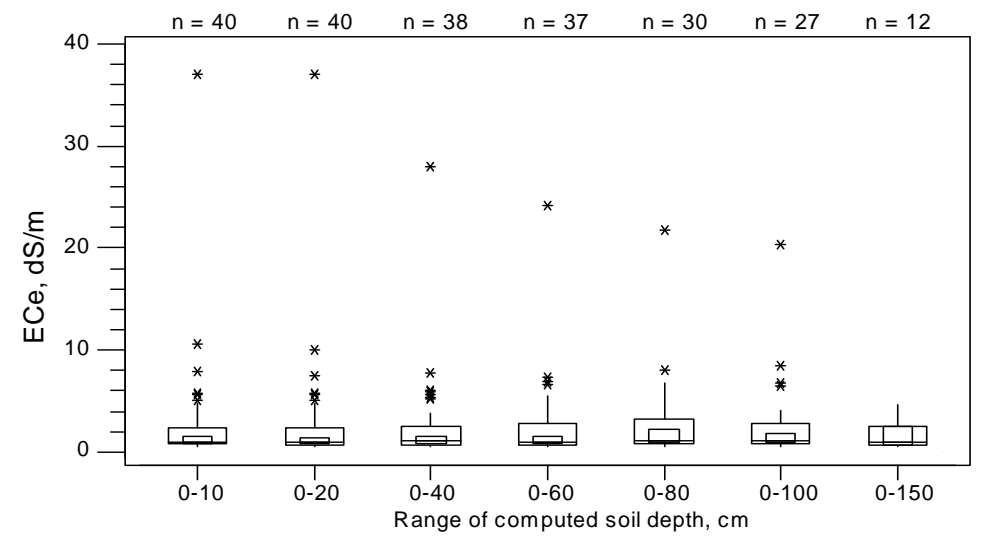

Figure 6. Boxplot of ECe for 7 depths in the soil profiles studied. Profile 15 is the farthest outlier for all depths except for $150 \mathrm{~cm}$, a depth not reached in this site. The value of $\mathrm{n}$ is the number of computed profiles for each depth. 

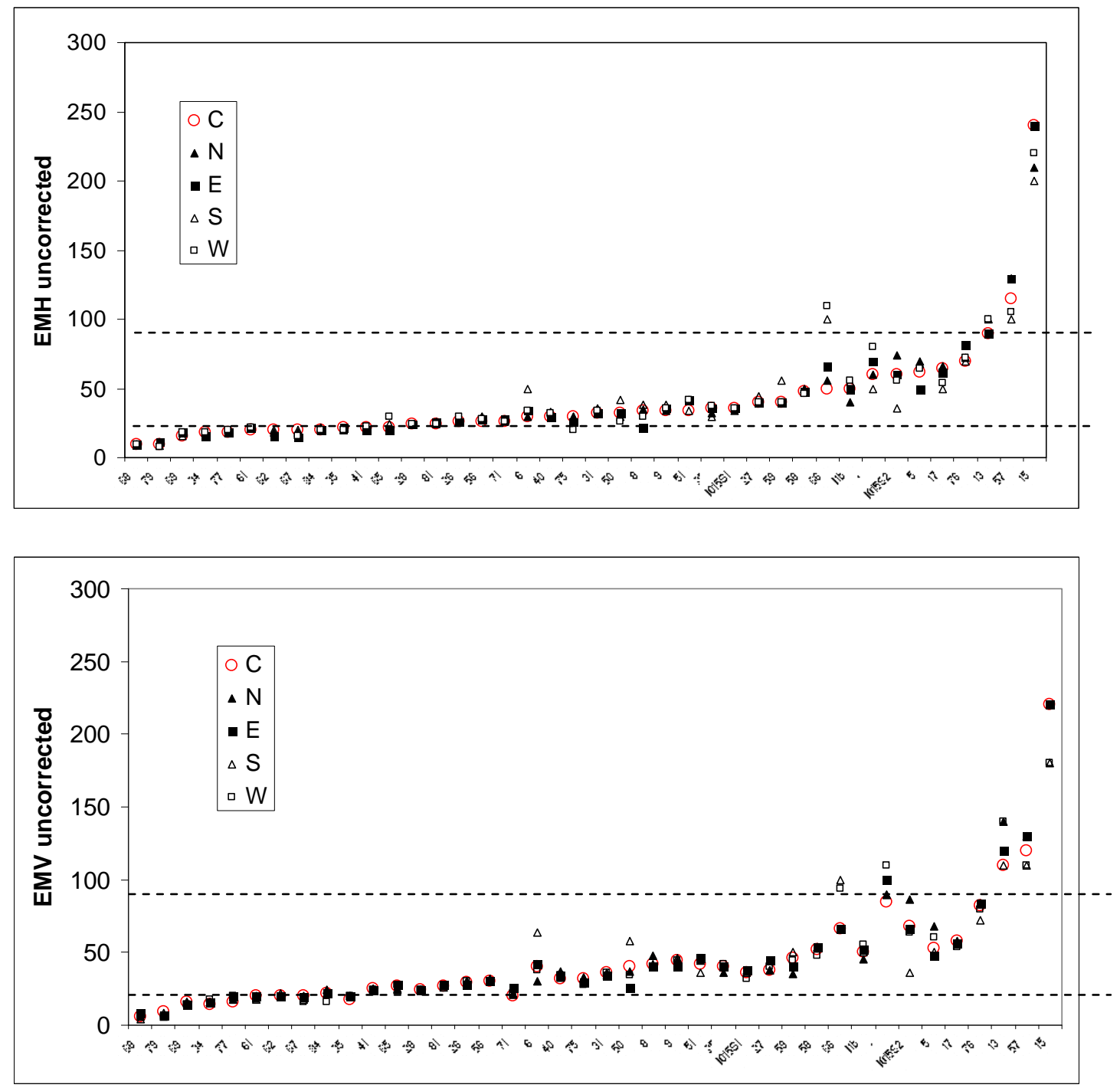

Figure 7. Uncorrected horizontal and vertical EMI readings at the augering point (C) and $2 \mathrm{~m}$ to the North, East, South, and West in each site. The profiles are ranked in the $\mathrm{x}$-axis by ascending horizontal EMI reading at $\mathrm{C}$ point. Dashed lines mark scale changes in the EM38 dial.

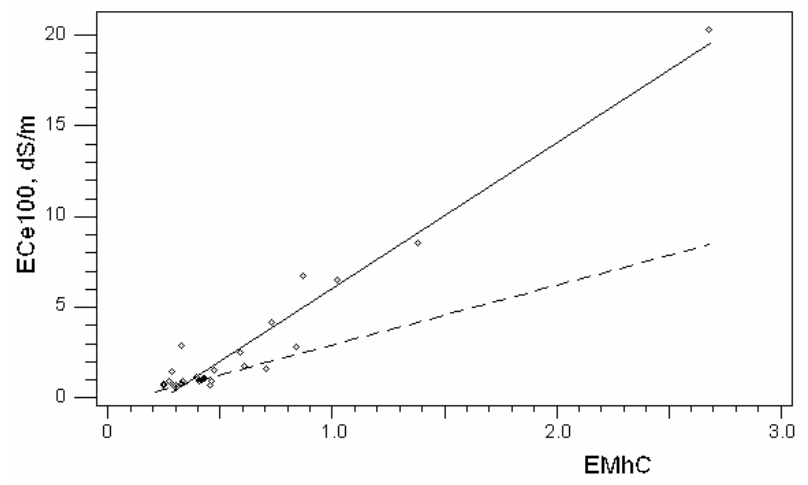

Figure 8. Scatter diagram illustrating the linear model fit for ECe100 and EMh C, with two regression lines adjusted by the least squares method (solid), and by LTS method (dashed). 


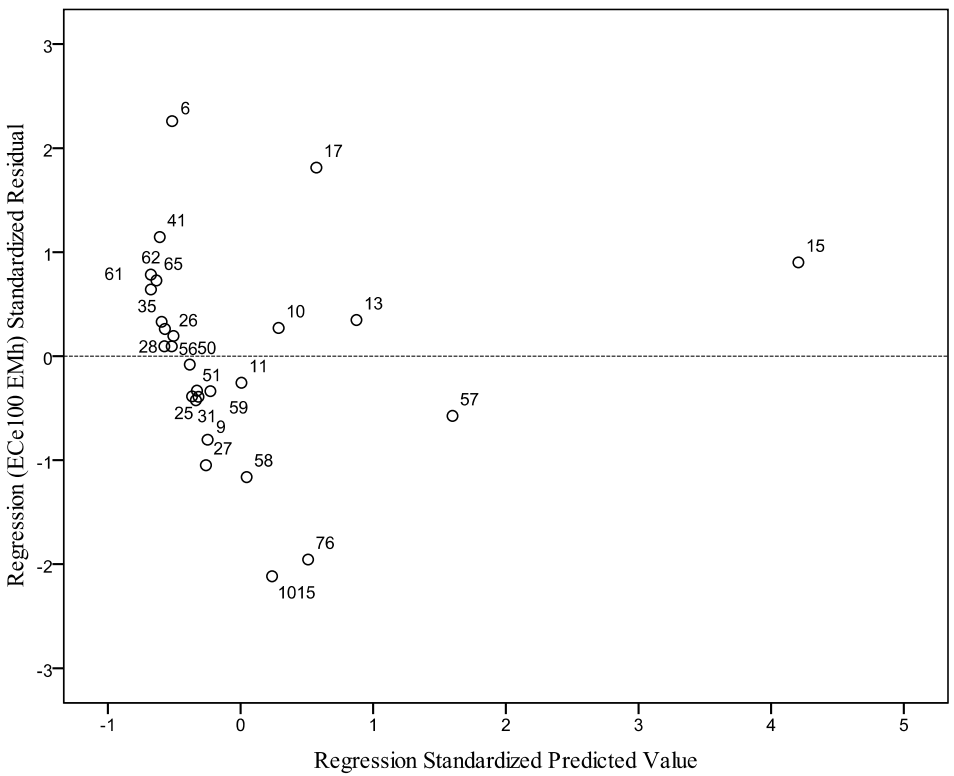

Figure 9. ECe/EMh ordinary least squares regression standardized residuals indicating the presence of outliers. 